\title{
Healthcare in Uttar Pradesh: Special Reference to Comparative Muslim Majority Districts
}

\section{Ashish KS* and Ayesha K}

Department of Economics, Kamala Nehru College, University of Delhi, India

\begin{abstract}
This paper seeks to analyse the healthcare climate within Uttar Pradesh, with special emphasis on the top 5 comparative Muslim majority districts (as \% of District population) for the same. It does so by comparing the collective performance of the identified States with the state averages for Uttar Pradesh for a limited number of healthcare indices via data available from the Annual Health Survey 2011. The health indices being covered include treatment available for population diagnosed with acute illness, regularity of treatment for diagnosed chronically ill populace, extent of Ante Natal care, parameters of delivery care, facilities in terms of Post Natal care, coverage of relevant female population under JSY - Janani Suraksha Yojana, differentials among birth registration, and finally, mortality rates for infants and children. The primary focus of the paper is the situation of women and children - the sections of population that are often the last to receive healthcare in India's deeply patriarchal society.

The state of Uttar Pradesh has been chosen for a number of reasons - primary among which are the sizeable population, variation of indices across the State in terms of averages, and the availability of reliable data for a secular analysis.
\end{abstract}

Keywords: Annual health survey; Janani suraksha yojana; Patriarchal society; Social stigmas

\section{Introduction}

Uttar Pradesh is the fourth largest State of India in terms of area, with a collective population that secures UP the title of the most populous country subdivision in the world. Needless to say, it is the most populous State of India.

The large population ensures that Uttar Pradesh offers diversity in terms of human experiences across all parameters that may be relevant to economic, sociological or anthropological research. As per 2011 census records, Uttar Pradesh is home to the maximum number of Hindu and Muslim population [1]. This fact gains credibility due to the fact that it is the most populous State in India, as mentioned previously. This diversity of experiences coupled with the enormous number of experiences in of themselves, makes Uttar Pradesh the frontrunner when it comes to choosing a region to focus this paper on.

As is the case with high population density areas historically, Uttar Pradesh has faced, and continues to face, monumental challenges in terms of healthcare development for the masses. The sheer number of people makes the implementation of any policy extremely difficult, and often no amount of planning is sufficient to overcome certain aspects of these challenges, due to deep-rooted social stigmas prevalent in Indian society.

On a national average, Muslims have lower wealth, consumption, and educational attainment, and face worse access to state services compared to the majority Hindus [2]. In such a scenario, they may be expected to perform worse than their Hindu counterparts in terms of availing healthcare facilities, or having access to the same in the first place. Based on this premise, the five Muslim majority districts of Uttar Pradesh, as a percentage of district population (as per 2011 Census) were identified as follows Rampur (50.57\%), Moradabad (47.11\%), Bijnor (43.04\%), Saharanpur (41.95\%), and Muzaffarnagar (41.30\%) respectively. The paper utilises AHS Uttar Pradesh 2011 data to measure access and utilisation of healthcare facilities in Uttar Pradesh and across the identified districts. In doing so, it considers 9 parameters to measure the healthcare facilities, namely - treatment available for population diagnosed with acute illness, regularity of treatment for diagnosed chronically ill populace, extent of Ante Natal care, parameters of delivery care, facilities in terms of Post Natal care, coverage of relevant female population under JSY - Janani Suraksha Yojana, differentials among birth registration, and finally, mortality rates for infants and children.

\section{Literature and Content}

There has been some research on the access to healthcare facilities on the basis of geography and socio-economic divisions. Professor Vijaya Kharikar [3], in her paper discussing maternal and child healthcare for Muslims concludes on the basis of secondary data, that socio-economic and demographic characteristics make differences in the use of maternal and child health care services [4]. Rama Baru et al. [5] discuss the inequities in access to healthcare services in India on the basis on caste, class, and region. They conclude that there is widespread inequity in access based on the aforementioned grounds and identify key areas that require urgent attention - one of which is the immediate need for healthcare to become a national priority. Jean Dreze et al. in their article regarding food and nutrition conclude with the urgent attention that dietary improvements, antenatal care, effective breast feeding and by other means of malnutrition eradication must be paid to improve India's health status.

While the collective performance of the districts may not be dismal in totalitarian terms on comparison with Uttar Pradesh averages, it is important to understand why there may exist wide variations in

*Corresponding author: Ashish KS, Department of Economics, Kamala Nehru College, University of Delhi, India, Tel: 8826081644; E-mail: ashishsedai7@gmail.com

Received February 02, 2016; Accepted April 14, 2016; Published April 18, 2016

Citation: Ashish KS, AyeshaK (2016) Healthcare in Uttar Pradesh: Special Reference to Comparative Muslim Majority Districts. J Glob Econ 4: 188. doi:10.4172/23754389.1000188

Copyright: ( 2016 Ashish KS, et al. This is an open-access article distributed under the terms of the Creative Commons Attribution License, which permits unrestricted use, distribution, and reproduction in any medium, provided the original author and source are credited. 
the performance of the same. Uttar Pradesh is in need to substantial funding and development in terms of the healthcare sector as evidenced by the consistent appearance of the same at very low levels in all manner of human development indices. On a pan India level, it is one of the States identified as being in need to urgent attention and has been subjected to special measures in terms on a multitude of healthcare schemes being launched and research done into the identification of key areas wherein implementation is running astray. Specialised District Management Units have been set up to monitor the same $^{1}$. In light of these initiatives, we will now review the performance of the State and aforementioned Districts.

\section{Analysis}

The upcoming analysis is based on data from the 2010-2011 Annual Health Survey of Uttar Pradesh conducted by the Government of India. We look at each aforementioned index one by one and contrast the collective performance of the identified districts with the Uttar Pradesh averages.

\section{Illness and treatment}

In this instance, the identified districts are collectively performing better than the State average, in case of males and females across rural and urban areas. A marginally higher proportion of the acutely ill populace in these districts are taking treatment from all forms of healthcare practitioners (Figure 1).

We move on to the next index, which is those suffering from chronic illnesses and receiving regular treatment for the same (Figure 2).

While the collective performance of the identified districts is marginally better in terms of rural access to regular treatment for those diagnosed with chronic diseases, it is the UP average that is better off in case of the urban population. Considering the fact that it is the rural areas where access to essential services is more severely limited due to prevalence of social stigmas, there appear to be signs that these Muslim majority districts have identified these challenges and are somehow working to combat them. However this is a nascent stage of the analysis and nothing can be said about this phenomenon without more evidence and research.

\section{Maternal health coverage - JSY}

Consider next, the coverage provided by the Janani Suraksha Yojana - which is one of the most important programmes under the overall umbrella of NRHM aimed at reducing Maternal Mortality Ratio and Neo-natal Mortality Rate by promoting institutional deliveries. Under the Scheme, cash incentives are provided to mothers and they are facilitated by Accredited Social Health Activists (ASHAs) to deliver their babies in a health facility. There are also provisions for cost reimbursement for transport and incentives to ASHAs for encouraging mothers to opt for institutional delivery. The scheme is fully sponsored by the Central Government and is implemented in all States and Union Territories, with special focus on low-performing States. There is also a provision for roping in the private sector by giving accreditation to willing private hospitals/nursing homes for providing delivery services. The Scheme has been implemented in all the 9 AHS States since $2005^{2}$ (Figure 3).

It is clear from the data that Uttar Pradesh on an average has

1 National Rural Health Mission Website, State wise information - Uttar Pradesh 2 Annual Health Survey, 2010-2011 Fact Sheet, Uttar Pradesh

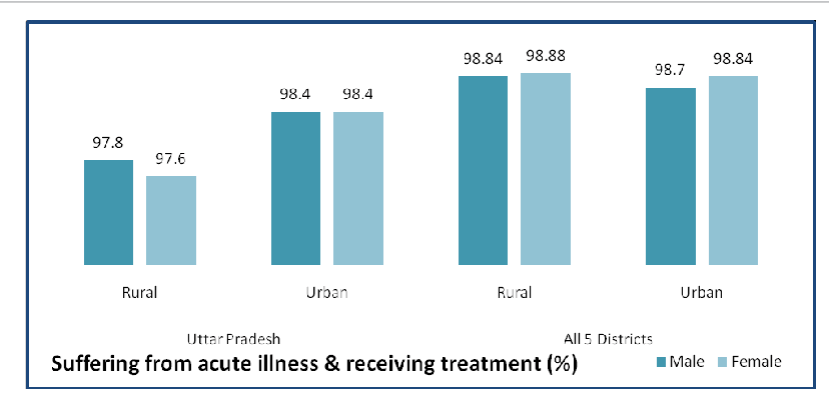

Source: AHS 2011

Figure 1: Percentage of people suffering from acute illness and receiving treatment.

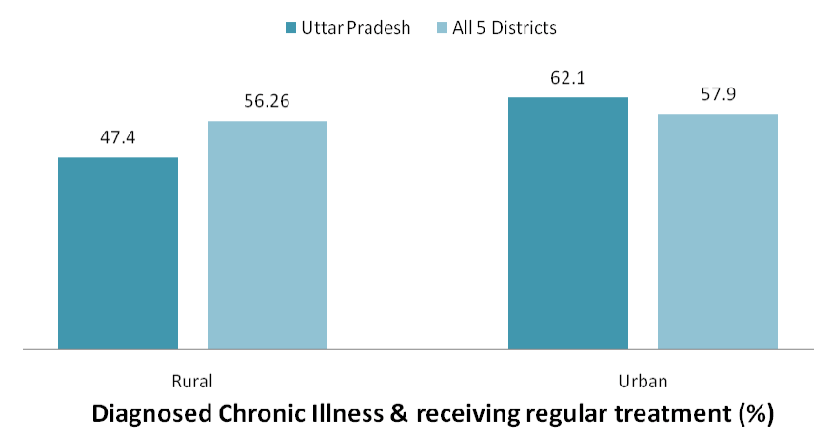

Source: AHS 2011

Figure 2: Percentage of people diagnosed chronic illness and receiving regular treatment.

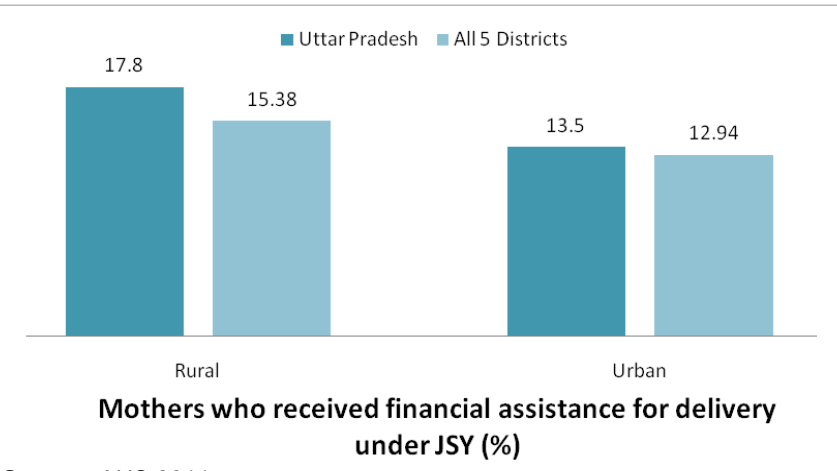

Source: AHS 2011

Figure 3: Percentage of mothers who received financial assistance for delivery under JSY.

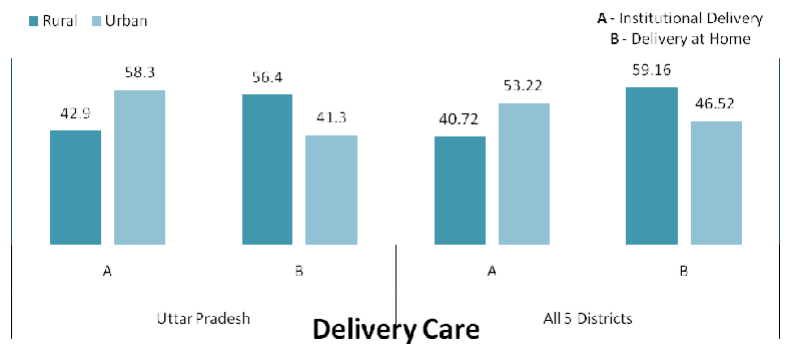

Source: AHS 2011

Figure 4: Delivery care. 
integrated the JSY in a better manner compared to the integration of the same on a collective basis by the identified districts. The districts as well as the overall State has performed better in the rural setup as opposed to the urban one in terms of financial assistance for delivery for mothers under the JSY. However, the urban-rural differential could exist due to the overall better economic status of women in urban areas, limiting the need for seeking financial assistance under the scheme for the same.

\section{Maternal health indices}

We next collectively consider three maternal health indices, which cover the antenatal care (ANC), Delivery care, and Post-natal care available to mothers in Uttar Pradesh (Figure 4).

Rural institutional deliveries for the 5 districts collectively are almost at par with the State average. The same may be said in case of urban institutional deliveries, as evident in the graphs. Consequently, the rural and urban at-home deliveries are also almost the same, with the 5 districts having a marginally worse off performance collectively (Figures 5 and 6).

Uttar Pradesh on an average, as well as the identified districts collectively, perform abysmally in case of full Antenatal check-ups for mothers. The reported figures are in single digits while measuring in terms of percentage figures. Once again, the 5 districts collectively perform better the State averages on the rural front, with a greater proportion of mothers receiving full Antenatal check-ups. However, the performance of the same on the urban front must be proactively addressed if improvements are to be seen.

The 5 districts however, must address the post natal check-ups for mothers as a greater proportion of their population does not receive said benefits in comparison to the State average. Uttar Pradesh performs marginally better than the 5 districts collectively on an average in terms of post natal check-ups for mothers within a week of delivery.

\section{Birth registration}

There are prevalent notions in terms of the instances of birth registration among Indian Muslims, wherein they are believed to be reluctant to register the births of their children for all manner of reasons. Birth registration data for 2011 as per government records is as follows - (Figure 7).

There are very minor marginal differences in birth registration among the 5 Muslim majority districts collectively, and the State averages both in terms of rural and urban areas. While Uttar Pradesh is marginally better in terms of reporting ad registering the births of children, the identified districts are not far behind in this regard.

\section{Mortality}

Consider finally, the Infant Mortality Rates (IMR) and Under 5 Mortality Rates (U5MR) for Uttar Pradesh and identified districts (Figure 8).

Bijnor has been excluded from this data set due to non-availability of data in case of urban areas in Bijnor for this index.

However, it is clearly noticed that mortality rates for infants as well as children are lower in case of the collective performance of the 5 districts, as compared to Uttar Pradesh averages. Despite underperforming in a number of relevant health indices, these districts manage to gain an upper hand in this index. Geruso and Spears [6] analyse the prevalence of in house latrines and cultural connotations of

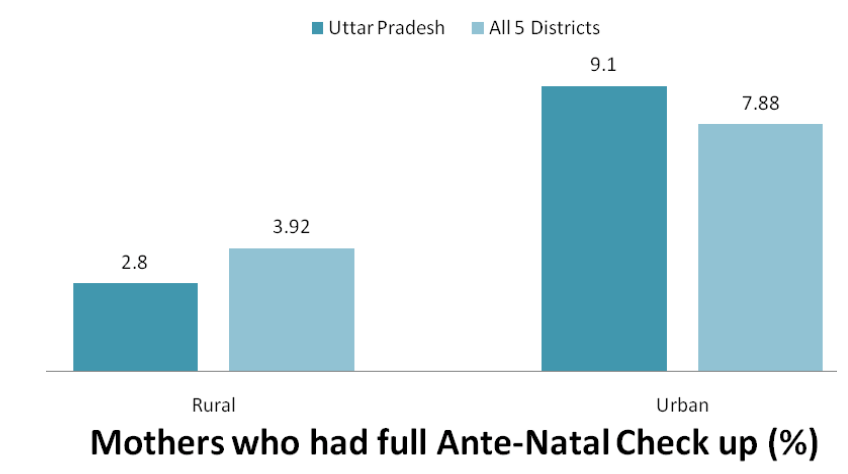

Source: AHS 2011

Figure 5: Percentage of mothers who had full ante-natal check up.

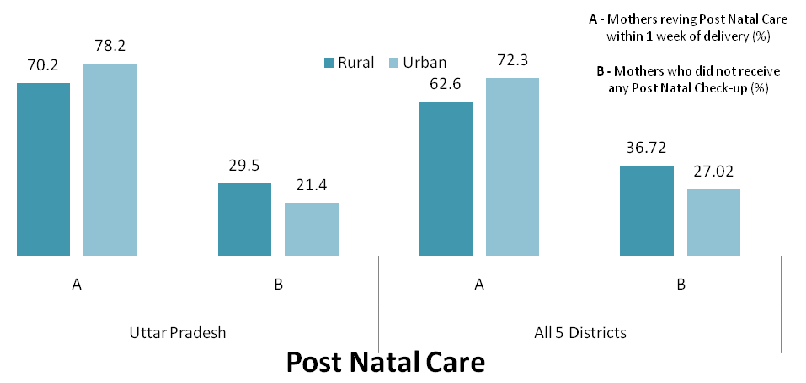

Source: AHS 2011

Figure 6: Post natal care.

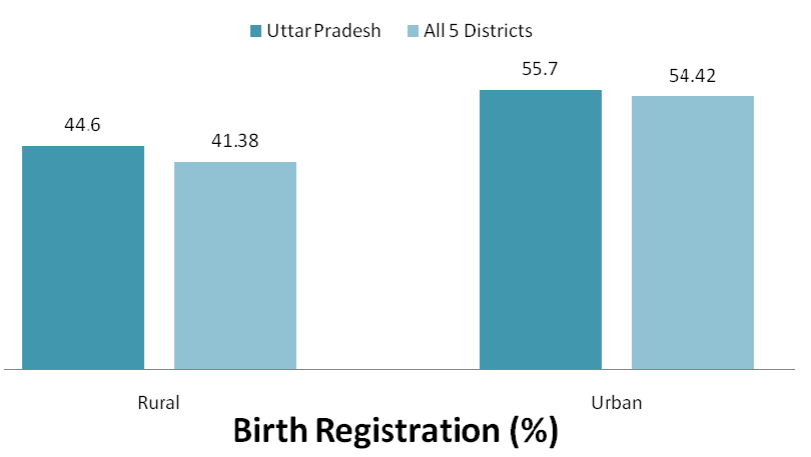

Source: AHS 2011

Figure 7: Percentage of birth registration.

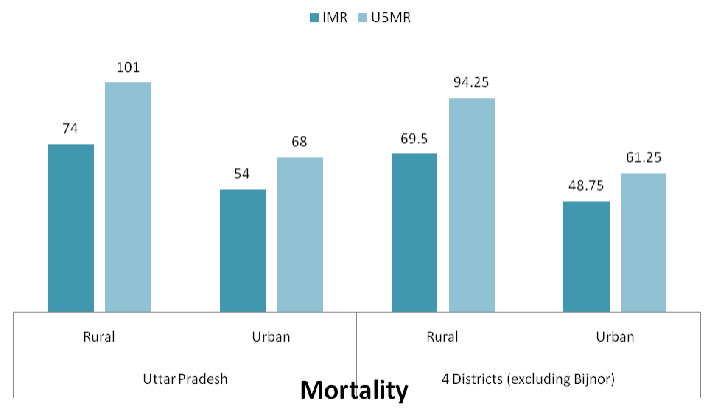

Source: AHS 2011

Figure 8: Mortality. 
Citation: Ashish KS, Ayesha K (2016) Healthcare in Uttar Pradesh: Special Reference to Comparative Muslim Majority Districts. J Glob Econ 4: 188. doi:10.4172/2375-4389.1000188

Page 4 of 4

open defecation to explain this 'paradox of Muslim mortality' in India, in their paper about the same.

\section{Conclusion}

In a few health indices, the collective performance of the 5 districts outshines the Uttar Pradesh averages, and in some it does so categorically for the rural areas. However, there appears to be a disturbing trend of underperformance by these 5 districts in integral indices such as implementation of JSY, Delivery care, and Post natal care. All three are important determinants of maternal health and the consistent neglect in this case is evident with the featuring of one of the districts, i.e. Saharanpur, in the official list of 57 common districts featuring in top 100 districts in order of Infant Mortality Rate and top 25 administrative divisions (Commissionrait) in order of Maternal Mortality Ratio. There is therefore an urgent need to address maternal health in Uttar Pradesh, with special emphasis being laid on these 5 districts - namely - Rampur, Moradabad, Bijnor, Saharanpur, and Muzaffarnagar.

\section{References}

1. Census of India (2011) C-1 Population by religious community table. Annual Health Survey.

2. Michael G, Dean S (2015) Neighbourhood Sanitation and Infant Mortality. National Bureau of Economic Research.

3. Khairkar V (2013) Issues of Maternal and Child Health Care Services among Muslims in Selected Cities of India. International Journal of Social Sciences, Language and Linguistics 38: 1110-1121.

4. Vijaya PK (2013) Issues of Maternal and Child Health Care Services among Muslims in Selected Cities of India Issues of Maternal and Child Health Care Services among Muslims in Selected Cities of India. International Journal of Social Sciences, Language and Linguistics.

5. Rama Baru (2010) Inequities in Access to Health Services in India: Caste, Class and Region. Economic and Political Weekly 45: 49-58.

6. Geruso M, Dean S (2015) Neighbourhood Sanitation and Infant Mortality National Bureau of Economic Research. 